AperTO - Archivio Istituzionale Open Access dell'Università di Torino

\title{
Emerging roles of Fgf14 in behavioral control
}

\section{This is the author's manuscript}

Original Citation:

Availability:

This version is available http://hdl.handle.net/2318/1686134

since 2019-01-08T15:28:25Z

Published version:

DOI:10.1016/j.bbr.2018.08.034

Terms of use:

Open Access

Anyone can freely access the full text of works made available as "Open Access". Works made available under a Creative Commons license can be used according to the terms and conditions of said license. Use of all other works requires consent of the right holder (author or publisher) if not exempted from copyright protection by the applicable law. 
Emerging roles of Fgf14 in behavioral control

\section{AUTHORS:}

Eriola Hoxha*a,b, Andrea Marcinnò*a, Francesca Montarolo ${ }^{\mathrm{a}}$, Linda Masante ${ }^{\mathrm{a}}$, Ilaria Balbo ${ }^{\mathrm{a}, \mathrm{b}}$, Francesco Ravera ${ }^{\mathrm{a}, \mathrm{b}}$, Fernanda Laezza $^{\mathrm{c}}$, Filippo Tempia ${ }^{\mathrm{a}, \mathrm{b}, \mathrm{d}}$

*These authors contributed equally

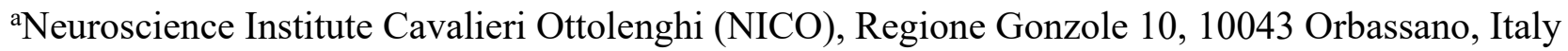

bepartment of Neuroscience, University of Torino, Corso Raffaello 30, 10125, Torino, Italy

'Department of Pharmacology and Toxicology, University of Texas Medical Branch, Galveston, TX, USA

${ }^{\mathrm{d} N a t i o n a l ~ N e u r o s c i e n c e ~ I n s t i t u t e ~(I t a l y), ~ C o r s o ~ M a s s i m o ~ D ' A z e g l i o ~ 52, ~} 10126$ Torino, Italy

e-mail addresses:

eriola.hoxha@unito.it

andrea.marcinno@edu.unito.it

francesca.montarolo@unito.it

linda.masante@unitn.it

ilaria.balbo@unito.it

francesco.ravera@edu.unito.it

felaezza@utmb.edu

filippo.tempia@unito.it

\section{CORRESPONDING AUTHORS:}

Filippo Tempia

Neuroscience Institute Cavalieri Ottolenghi

Regione Gonzole 10

10043 Orbassano

Italy

and

Eriola Hoxha

Neuroscience Institute Cavalieri Ottolenghi

Regione Gonzole 10

10043 Orbassano 
Italy 


\begin{abstract}
Sexual disturbances, and aggressivity are a major social problem. However, the molecular mechanisms involved in the control of these behaviors are largely unknown. FGF14, which is an intracellular protein controlling neuronal excitability and synaptic transmission, has been implied in neurologic and psychiatric disorders. Mice with Fgfl4 deletion show blunted responses to drugs of abuse. By behavioral tests we show that male Fgfl4 knockout mice have a marked reduction of several behaviors including aggressivity and sexual behavior. Other behaviors driven by spontaneous initiative like burying novel objects and spontaneous digging and climbing are also reduced in Fgfl4 knockout mice. These deficits cannot be attributed to a generalized decrease of activity levels, because in the open field test Fgfl4 knockout mice have the same spontaneous locomotion as wild types and increased rearing. Our results show that Fgfl4 is important to preserve a set of behaviors and suggest that fine tuning of neuronal function by $\mathrm{Fgfl} / 4$ is an important mechanism of control for such behaviors.
\end{abstract}

\title{
HIGHLIGHTS
}

- Deletion of Fgf14, which is known to fine tune neuronal function, causes a reduction of climbing, digging and burying novel objects.

- These behavioral deficits cannot be attributed to motor impairment, because Fgf14 knockout mice have normal spontaneous locomotion in a novel environment.

- Fgf14 knock-out mice show reduced aggressivity and sexual behavior.

- These deficits in inter-individual interaction cannot be attributed to impaired sociability, because Fgf14 knock-out mice show a normal preference for a conspecific relative to an object.

\section{KEY WORDS}

Fgf14; aggressivity; sexual behavior; spontaneous behavior; sociability; mouse

\section{ABBREVIATIONS}

$\mathrm{Fgfl} 4^{-/-}$mice: mice with a targeted deletion of the $\mathrm{Fgfl} 4$ gene

SEM: standard error of the mean

\section{INTRODUCTION}

Disorders that include, alterations of sexual behavior and aggressivity are controlled by complex brain networks including the main olfactory system, basal ganglia (mainly ventral striatum and 
ventral pallidum), prefrontal cortex, ventral hippocampus, amygdala and hypothalamus [1], but little is known about the molecular determinants of such diseases.

Mutations of the FGF14 gene were initially reported in a spontaneously occurring human disease, the spino-cerebellar ataxia type 27 (SCA27), which, in addition to cerebellar symptoms, is associated to deficits in cognition, memory and behavior [2-3]. More recently, FGF14 has been implied in a series of psychiatric and neurologic disorders by several large-scale genome-wide association studies, which identified this gene as a potential molecular determinant of addictive behavior, schizophrenia, bipolar disorder, depression and epilepsy [4-11].

FGF14 is an intracellular protein that is related in sequence and structure to fibroblast growth factors, which are secreted, trophic molecules essential for proper development and function in a large variety of tissues [12]. In contrast to such fibroblast growth factors, some members of the FGF family (FGF11-14) are not secreted but act intracellularly, where they bind to target proteins including voltage-gated $\mathrm{Na}^{+}$(Nav) channels [13-15]. More specifically, FGF14 binds to the Cterminal domain of Nav1.1, Nav1.2 and Nav1.6 [16-17]. The binding of FGF14 modulates the function of the channel, in an isoform specific manner [16-17]. Furthermore, the biophysical properties of Nav channels are regulated by phosphorylation of FGF14 by several kinases, like GSK3, which are implied in psychiatric disorders [11].

Fgf14 is expressed in the mouse central nervous system from embryonic day 12.5 [18] and in the adult brain the highest levels of Fgfl4 expression have been found in cerebellum, basal ganglia, hippocampus, amygdala, cerebral cortex and thalamus [19-20], showing a large overlap with the regions critical for the control of food intake, sexual behavior and aggressivity.

Mice with a targeted deletion of the $\mathrm{Fgfl} 4$ gene ( $\mathrm{Fgfl} 4^{-/-}$mice) have a normal development of the central nervous system and a preserved overall brain anatomy [19]. In the adult brain, while the cerebellum and basal ganglia of $\mathrm{Fgfl}^{-/-}$mice are indistinguishable from wild types, in the hippocampus they show a disrupted inhibitory GABAergic circuit associated with altered action potential generation [21].

$\mathrm{Fgfl}^{-/-}$mice recapitulate several features of psychiatric disorders like working memory deficits and decreased gamma frequency oscillations of cortical networks, reminiscent of findings in patients with schizophrenia [21]. Moreover, $\mathrm{Fgfl} 4^{-/-}$mice display a strong suppression of locomotor responses normally elicited by the administration of drugs of abuse like cocaine and amphetamine, and to the administration of a $\mathrm{D}_{2}$ dopamine receptor agonist [19]. These results suggest that $F g f 4^{-/-}$ mice might have a deficit in behaviors that are related to decreased responsiveness to dopamine. However, the underlying mechanisms might be more complex, because the dopaminergic pathways were found to be intact in Fgfl $4^{-/-}$mice [19]. The presence of such morphological and behavioral alterations suggests the presence of aberrant neuronal activity in the critical regions for the control of food intake, sexual behavior and aggressivity. These regions include the striatum, hippocampus, 
neocortex (especially prefrontal cortex) and amygdala [1]. Therefore, we hypothesized that some of these behaviors might be affected by Fgfl4 deletion.

\section{MATERIALS AND METHODS}

\subsection{Animals}

Two to four months old male $F g f 14^{-/-}$mice and their wild type littermates were used for all experimental paradigms. All the animals used were male. The $F g f 14^{-/-}$mice were obtained from Prof. Laezza Fernanda, University of Texas Medical Branch U.S.A. Adequate measures were taken to minimize pain and discomfort. All experimental procedures were carried out at NICO and approved by the Ethical Committee of the University of Torino and authorized by the Italian Ministry of Heath (authorization number: 822/2016-PR). Experiments have been carried out in accordance with the European Communities Parliament and Council Directives of 24 November 1986 (86/609/EEC) and 22 September 2010 (2010/63/EU).

\subsection{Behavioral tests}

Behavioral studies were performed in young adult male animals between 2 and 4 months, always during the light phase of the cycle. A general timeline of the behavioral tests is reported in Fig 1. The same animals underwent all of the behavioral tests reported in the timeline. Where needed, all behavioral procedures were video-recorded and scored by an individual blind to the genotype of the mouse.

\subsubsection{Spontaneous behavior}

For each mouse ( $\mathrm{n}=12$ wild type; $\mathrm{n}=12 \mathrm{Fgfl4^{-/ }}$ ) the evaluation of spontaneous behavior was performed as follows:

Mice were allowed to habituate to room for at least 45 minutes. Mice were removed from their home cages and individually placed in a clear cage (area $36 \times 21$, height $14 \mathrm{~cm}$ ) with standard supply of food and water. The experiment was performed with constant lighting conditions. Each trial was video recorded for 20 minutes while the operator was out of the room. Each video was analyzed off-line for 10 minutes, between the $5^{\text {th }}$ and $15^{\text {th }}$, by an individual blind to the genotype of the mouse. The ethologically-based behavioral checklist was similar to that described previously [22].

In particular, we measured the following parameters:

- $\quad$ Rearing free (front paws reaching upwards away from any cage wall while standing on hind limbs). 
- $\quad$ Rearing towards a cage wall (front paws reaching upwards on a cage wall while standing on hind limbs).

- $\quad$ Rearing towards central structure (front paws reaching upwards on that portion of grill where food and water are placed, while standing on hind limbs).

\section{- Digging.}

- Grooming (of any form).

- $\quad$ Climbing (jumping onto cage top with climbing along grill in inverted or hanging position).

- $\quad$ Stillness (motionless, with no behavior evident).

- Jumping (every vertical movement, with detachment of both hind limbs from the cage floor, which is not included as total climbing).

We assessed, for each type of behavior, three different time parameters:

- $\quad$ Total time (seconds) spent by the animal showing a single behavior.

- Number of episodes of a specific behavior.

- Mean time duration (seconds) of each episode for each specific behavior (this data was obtained by the division of total time spent for a specific behavior / number of episodes for the same behavior).

\subsubsection{Sexual behavior}

All mice (n=14 wild type; $\mathrm{n}=14 \mathrm{Fgfl4^{-/ }}$ ) were removed from their home cage and kept single caged (cage area $36 \times 16$, height $13 \mathrm{~cm}$ ) for two weeks before performing the test. Only sexually naive male mice were used, because they are unable to discriminate between oestrus and non oestrus females [23]. Mice were transported in the test room and were allowed to habituate to room setting for at least 45 minutes. A sexually naive female (randomly chosen in a group of 2-4 months aged C57BL/6 female mice) was introduced in the home cage of the tested mouse. Each female was used only once. Each trial was carried out maintaining constant setting and lighting conditions in the same room. The tests were videotaped for 15 minutes. Each video was analyzed off-line by a trained single operator blind to the genotype of each animal. The male-female interactions were screened through a behavioral checklist similar to that described by [23-24].

The parameters analyzed were:

Mounting (pelvic thrusting with physical contact between male and female pelvic regions).

Latency to mount (seconds) (if no mount could be detected during the entire duration of the test, this latency was set to 900 seconds).

Intromission (mounting associated with a stable frequency continuously for at least 3 seconds and if the female's anogenital area was elevated over the ground when finished). 
Social approach (including sniffing on the body or head of the female, anogenital sniffing, social grooming, barbering and chasing).

Avoidance (leaving the female, both on the horizontal and vertical plane).

Passive behavior (the female exhibits one of the items included in the category "social approach" while the male stands in a submissive attitude).

The statistical comparison between the two genotypes was applied to three different time parameters for each behavioral item, excluding latency measures:

- $\quad$ Total time (seconds) spent by the animal showing a single behavior.

- Number of episodes of a specific behavior.

- Mean time duration (seconds) of each episode of that specific behavior (these data were obtained with the division total time / number of episodes).

\subsubsection{Resident intruder test}

All mice (n=14 wild type; n=16 Fgfl4 $4^{-/}$) used for this test were removed from their home cage and kept single caged (cage area $36 \times 16$, height $13 \mathrm{~cm}$ ) for two weeks before being used as resident. This was in order to enhance their territorial attitude and to create a condition of mild social stress. Mice were transported in the test room and were allowed to habituate to room setting for at least 45 minutes. The test was carried out maintaining constant setting and lighting conditions. An intruder mouse of the same age and with a lower or same weight (intruders were group-housed C57BL/6 male mice) was placed in the home cage of the tested resident mouse. The intruders were used only once. The test was videotaped for 15 minutes. The analysis took place in a subsequent moment and was performed by a trained single operator blind to the genotype of each animal. The aggressive and territorial attitude of resident mice was assessed as previously described by [25].

- Attacking (wrestling).

- Latency to attack (seconds) (if no attack could be detected during the entire duration of the test, the attack latency was set to 900 seconds).

- Threatening (including chasing, all offensive postures and aggressive grooming).

- Social behavior (including sniffing on the body or head of the intruder, anogenital sniffing, social grooming and following).

- Individual interaction (the sum of the time spent in attack, threat and social behavior).

- Types of interaction (the behavioral pattern of the animals was studied by calculating the percentage of each type of behavior (i.e. social interaction, threatening and attacking) in relation to the total time of individual interaction).

The statistical comparison between the two genotypes was applied to three different time parameters for each behavioral item, excluding latency measures: 
- Total time (seconds) spent by the animal showing a single behavior.

- Number of episodes of a specific behavior.

- Mean time duration (seconds) of each episode of that specific behavior (these data were obtained with the division total time / number of episodes for each specific behavior).

\subsubsection{Open field}

Animals (n=8 wild type; $\mathrm{n}=11 \mathrm{Fgfl4^{-/ }}$ ) were tested in a 50 x $50 \mathrm{~cm}$ arena. The animal was placed in the corner of the open field and was allowed to explore the arena for $60 \mathrm{~min}$. The distance traveled in the open field and the time spent in the center zone were measured every 10 minutes .

\subsubsection{Three-chambered sociability test}

The mice (n=7 wild type; n=7 Fgfl $4^{-/}$) used for the experiment were transported to the test room and were allowed to habituate to room setting for at least 45 minutes. The apparatus, a custommade clear Plexiglas box partitioned into three chambers of equal size (length $20 \mathrm{~cm} x$ width 40.5 $\mathrm{cm} \times$ height $22 \mathrm{~cm}$ ), was designed as previously described [26]. The test was divided in two phases, habituation and social behavior.

Habituation. At the beginning of the test the mouse was confined in the middle chamber for 10 minutes. After this phase the doors were opened and the mouse was permitted to freely move in all chambers for other 10 minutes.

Social behavior. The test mouse was confined again in the middle chamber. An inverted empty wire cup (wire pencil cup, Galaxy Cup, Kitchen Plus, http://www.kitchen-plus.com) and a wire cup containing a stranger mouse (stranger) were placed into left and right chambers. The doors were re-opened and the mouse was allowed to explore all chambers for other 10 minutes. The movements of the test mice were videotaped from the top and their approaches were analyzed using Ethovision XT video track system (Noldus Information Technology, Wageningen, The Netherlands). The comparison of the time spent with stranger vs. empty wire cup indicated the sociability of animals. Stranger mice were housed in the same facility but had no prior contact with test mice. They were trained for two sessions of $15 \mathrm{~min}$ a day before the test. The observer remained in the room and only mice that at the end of $15 \mathrm{~min}$ did not grip to the wire cup were chosen.

\subsubsection{Marble burying test}

The test was performed as in Hoeffer et al. [27]. Mice were placed individually in large clean cages (area $36 \times 21$, height $14 \mathrm{~cm}$ ) containing five $\mathrm{cm}$ deep bedding. Twenty small black marbles were arranged in five spaced rows of four marbles. After a 30-min test period conducted under normal 
room lighting, mice were removed and the unburied marbles were counted. Marbles were considered buried if they were at least $2 / 3$ covered with bedding.

\subsection{Histological procedures}

$F g f 14^{-/-}$mice $(\mathrm{n}=3)$ and their wild type littermates $(\mathrm{n}=3)$ were anesthetized via intraperitoneal injection with ketamine (100 mg/kg body weight) and xylazine (10 mg/kg body weight) and perfusion-fixed with $4 \%$ paraformaldehyde in $0.12 \mathrm{M}$ phosphate buffer. The brains were removed and immersed in the same fixative at $4{ }^{\circ} \mathrm{C}$ for $18 \mathrm{~h}$ and then cryoprotected in $30 \%$ sucrose in 0.12 $\mathrm{M}$ phosphate buffer. The brains were frozen and serially cut by a freezing microtome in $50 \mu \mathrm{m}$ thick coronal sections and stained with cresyl violet. Volumetric analysis was performed on the basolateral amygdala complex by means of the StereoInvestigator software (MicroBrightField, Williston, VT, USA). The interval thickness between the serial sections analyzed was $300 \mu \mathrm{m}$.

\subsection{Real time RT-PCR}

mRNA expression levels of the dopamine D1 receptor (Drd1), D2 receptor (Drd2) and dopamine reuptake transporter DAT (Slc6a3) were evaluated by real time reverse transcription polymerase chain reaction (RT-PCR).

To obtain dissected brain regions, male mice (2-4 months old) were anesthetized by isoflurane inhalation and decapitated. Brains were removed immediately after decapitation and coronal sections were cut using a vibratome (Leica Microsystems GmbH, Wetzlar, Germany) following the coordinates of the mouse brain atlas [28]. From the slices, the prelimbic and infralimbic areas of the medial prefrontal cortex (mPFC), the nucleus accumbens $(\mathrm{Acb})$ and the caudate-putamen $(\mathrm{CPu})$ were dissected.

Total RNA from mPFC (mice: $\mathrm{n}=8$ wild type and $\mathrm{n}=9 \mathrm{Fgfl4^{-/ }}$ ), Acb (mice: $\mathrm{n}=4$ wild type and $\mathrm{n}$ $=5 \mathrm{Fgfl4^{-/ }}$ ) and $\mathrm{CPu}$ (mice: $\mathrm{n}=4$ wild type and $\mathrm{n}=5 \mathrm{Fgfl} 4^{--}$), was extracted using the Pure link RNA Mini Kit (Life Tecnologies), according to manufacture's instructions. Total RNA, for each region, was reversed transcripted at a final concentration of $20 \mathrm{ng} / \mu \mathrm{l}$, using the High-Capacity cDNA Reverse Transcription Kit (Thermo Fisher Scientific). For primers and probes, Applied Biosystems' TaqMan ${ }^{\circledR}$ Assay-on-demand-TM gene expression products were used. The catalogue number for each gene was Drd1 (Mm02620146_s1), Drd2 (Mm00438545_m1), Slc6a3 (Mm00438388_m1). Phosphoglycerate Kinase 1 (PGK1) (Mm00435617_m1) was used as the reference gene in the expression level analysis. Expression levels of target genes were calculated by the normalized comparative cycle threshold $(\mathrm{Ct})$ method $\left(2^{-\Delta \mathrm{Ct}}\right)$.

\subsection{Statistical analysis}


Statistical analyses were carried out by GraphPad Prism 5 (GraphPad Software Inc., La Jolla, CA, USA) and included two-tailed unpaired Student's t-test, Fisher's test and Mann-Whitney u-test. In all instances, $P<0.05$ was considered as statistically significant. Data were expressed as average \pm standard error of the mean (SEM).

\section{RESULTS}

\subsection{Abnormal spontaneous behavior of $\mathrm{Fgf14} 4^{-/}$mice}

The observation of spontaneous behavior of mice in their housing cages represents a rich source of information not biased by experimental manipulation. For this reason, in order to gain insight in the behavioral alterations of $\mathrm{Fgfl} 4^{-/-}$mice we started with a thorough assessment of their spontaneous behavior, compared to their wild-type littermates. The parameters considered were rearing (defined as lifting the forepaws and keeping them either free or leaning to a vertical surface like the cage wall or the cage central structure), digging, grooming, climbing, jumping and remaining still. For each behavior we counted the total number of episodes, the duration of each episode and the total time spent in that behavior. The results are reported in Table I. Fgfl $4^{-/-}$and wild type mice differed significantly in rearing, climbing and digging behaviors. Rearing wall and central structure behaviors differed between genotypes $(\mathrm{t}$ test, $\mathrm{t}(22)=2.465, \mathrm{p}=0.022$ and $\mathrm{t}(22)=3.025, \mathrm{p}=0.006$; respectively, Fig. 2A, D and Table I). $F g f 14^{-/-}$mice reared significantly less often toward the central structure ( $\mathrm{t}$-test, $\mathrm{t}(22)=2.374, \mathrm{p}=0.027$, Fig. $2 \mathrm{E}$ and Table I), but with a significantly increased duration of each episode ( $\mathrm{t}$-test, $\mathrm{t}(22)=4.714, \mathrm{p}=0.0001$, Fig. $2 \mathrm{~F}$ and Table I). Furthermore, an increased duration of each episode was observed for all types of rearing, also for free rearing and rearing wall behaviors ( $\mathrm{t}$-test, $\mathrm{t}(22)=2.415, \mathrm{p}=0.025$ and $\mathrm{t}(2)=5.011, \mathrm{p}=0.0001$; respectively, Fig. 2C, I and Table I). Digging behavior was significantly reduced in $\mathrm{Fg} f \mathrm{4}^{-/}$mice compared to their wild type littermates (t-test, $\mathrm{t}(22)=3.641, \mathrm{p}=0.001$, Fig. $3 \mathrm{~A}$ and Table I). A reduction was also observed in the number of episodes for digging in $\mathrm{Fgfl}^{-/-}$mice ( $\mathrm{t}$ test, $\mathrm{t}(22)=4.060, \mathrm{p}=0.0005$, Fig. $3 \mathrm{~B}$ and Table I). The climbing behavior was reduced in $\mathrm{Fgfl}^{-/-}$mice both as total time and as number of episodes ( $\mathrm{t}$ test, $\mathrm{t}(22)=2.624, \mathrm{p}=0.015$ and $\mathrm{t}(22)=3.034, \mathrm{p}=0.006$; respectively, Fig. 4A, $\mathrm{B}$ and Table I). Grooming, jumping and stillness behaviors did not differ between genotypes (t-test, $\mathrm{p}>0.05$ ). However, for stillness behavior there was a significant increase in the duration of each episode in $\mathrm{Fgfl}^{-/-}$mice (Table I).

\subsection{Reduced marble burying by $\mathrm{Fg} 14^{-/}$mice}

The marble burying test revealed a more than tenfold and significant difference between genotypes, with a reduced number of buried marble spheres for $\mathrm{Fgfl}^{-/-}$mice $(0.8 \pm 0.55)$ compared to wild types $(10.75 \pm 1.73)(\mathrm{t}$ test, $\mathrm{t}(16)=6.007, \mathrm{p}<0.0001$, Fig. 5). 


\subsection{Reduced sexual behavior of $\mathrm{Fg} f 14^{-/-}$mice}

The sexual behavior of $F g f l 4^{-/-}$male mice resulted profoundly altered. The latency to the first mount was significantly prolonged in $F g f 14^{-/-}$mice $(\mathrm{t}$ test, $\mathrm{t}(26)=5.331, \mathrm{p}=0.0001$, Fig. $6 \mathrm{~A}$ and Table II). Both mean time of mounting and duration of each episode were significantly reduced in $F g f 14^{-/-}$mice ( $\mathrm{t}$ test, $\mathrm{t}(26)=2.484, \mathrm{p}=0.020$ and $\mathrm{t}(26)=3.449, \mathrm{p}=0.002$ respectively, Fig. $6 \mathrm{~B}, \mathrm{D}$ and Table II). The number of mounts was significantly reduced in $F g f 14^{-/-}$mice ( $\mathrm{t}$ test, $\mathrm{t}(26)=3.234, \mathrm{p}=$ 0.003, Fig. 6C and Table II). Furthermore, the number of $\mathrm{Fgfl}^{-/-}$males performing mounting was very low ( 1 of 14 mice) relative to their wild type littermates (12 of 14 mice) (Fisher's test, $\mathrm{p}<$ 0.0001, Fig. 6E). Intromission, avoidance and affiliation approach were not significantly different between genotypes $(\mathrm{p}>0.05$, Table II). An interesting data that arise from this test, in accord with a reduced sexual interaction, is the significant increase of passive behavior in $\mathrm{Fg} / 4^{-/-}$mice (t test, $\mathrm{t}(26)=4.793, \mathrm{p}<0.0001$, Fig. $6 \mathrm{~F}$ and Table II).

\subsection{Reduced aggressive behavior of $\mathrm{Fg} / \mathrm{F}^{-/-}$mice in the resident/intruder test}

In the resident/intruder test, the latency of attacking the intruder mouse and the number of episodes were comparable between genotypes ( $p>0.05$, Table III). On the contrary, the time spent attacking and the duration of each attack were significantly reduced in $F g f 14^{-/-}$mice $(\mathrm{u}=71.50, \mathrm{p}=0.045$ and $\mathrm{t}(28)=2.786, \mathrm{p}=0.0095$, respectively, Fig. 7A, C and Table III). The number of episodes for attack was comparable between genotypes ( $\mathrm{p}>0.05$, Fig. 7C) $\mathrm{Fgfl} 4^{-/-}$mice showed a significant reduction in time threatening the intruder mouse, number of episodes and duration of each threat episode $(\mathrm{t}$ test, $\mathrm{t}(28)=4.007, \mathrm{p}=0.0004 ; \mathrm{t}(28)=4.076, \mathrm{p}=0.0003$ and $\mathrm{t}(28)=2.346, \mathrm{p}=0.026$; respectively, Fig. 7D, E, F and Table III). On the other hand, $\mathrm{Fgfl} 4^{-/-}$mice spent more time in social interaction than their wild type littermates $(\mathrm{t}(28)=8.769, \mathrm{p}<0.0001$, Fig. $7 \mathrm{G}$ and Table III). Moreover, the percentage of time spent in social behavior relative to the total time of all types of inter-individual interaction was greater in $\mathrm{Fgfl} 4^{-/-}$mice than controls $\left(97.59 \%\right.$ for $\mathrm{Fgfl} 4^{-/-}$mice and $78.25 \%$ for wild type, Fig. 7H).

The amygdala plays a pivotal role in the integration and expression of aggressivity and the volume of this structure has been reported to be altered in subjects with a history of aggressivity or violence [29-32]. We hypothesized that in $\mathrm{Fgfl}^{-/-}$mice the reduced levels of aggressivity could be related to an abnormal volume of the amygdala. With a stereological analysis of the amygdala, the volume in $\mathrm{Fgfl}^{-/-}$mice was $0.770 \pm 0.050 \mathrm{~mm}^{3}$, which was not significantly different compared to wild type $\left(0.807 \pm 0.042 \mathrm{~mm}^{3} ; \mathrm{p}>0.05\right.$, Fig. $\left.7 \mathrm{I}, \mathrm{J}\right)$. This result suggests that the reduction in aggressivity is not due to an altered volume of the amygdala.

\subsection{Normal sociability of $\mathrm{Fg} f 14^{-/-}$mice in the three-chambered test}


Modifications of social behavior might in some cases underlie alterations in sexual and aggressive behavior. To exclude the hypothesis of a reduced social interaction of $F g f l 4^{-/-}$mice with wild type mice of the same sex we performed the three-chambered test. The time spent in the chamber with the stranger mouse was significantly greater than the time spent in the chamber with the inanimate object for both wild type ( $\mathrm{t}$ test, $\mathrm{t}(12)=4.21, \mathrm{p}=0.0012$; Fig. $8 \mathrm{~A}$ ) and $\mathrm{Fgfl} 4^{-/-}$mice (t test, $t(12)=3.21, p=0.0074$; Fig. 8A). These results demonstrate that the deficit in sexual and aggressive behavior of $\mathrm{Fgfl} 4^{-/-}$mice is not attributable to changes in social interaction.

\subsection{Preserved locomotor activity and exploratory behavior of $\mathrm{Fg} 14^{-/-}$mice in the open field test}

The reduction of some behaviors of $F g f 14^{-/-}$mice, like aggressivity or sexual approach, might be due to a to a reduced locomotor activity or a lack of interest to explore a novel environment. To address this hypothesis, mice were subjected to the open field test. No significant differences were observed between genotypes for the distance traveled in the open field (two way ANOVA repeated measures, $F(1,15)=0.2633, \mathrm{p}=0.62$; Fig. $8 \mathrm{~B}$ ). Moreover, the distance traveled in the arena in the first 10 minutes was comparable between genotypes (Mann-Whitney test, $u=22, p=0.20$ ) indicating a normal exploratory behavior of $\mathrm{Fgfl} 4^{-/-}$mice in a new environment. The time spent on the center zone of the open field was comparable between genotypes (two way ANOVA repeated measures, $F(1,85)=0.17, p=0.68$; Fig. $8 \mathrm{~B})$. These results demonstrate that the reduction of aggressive or sexual behavior is not linked to deficits in exploratory or locomotor activity.

\subsection{Preserved dopamine receptors and transporter gene expression in $\mathrm{Fgfl} 4^{-/-}$mice}

We quantified by real time RT-PCR the gene expression of the dopamine receptor D1 (Drd1), the dopamine receptor D2 (Drd2) and the dopamine reuptake transporter (Slc6a3) (Fig. 9) in the mPFC, $\mathrm{Acb}$, and $\mathrm{CPu}$, in wild type and $\mathrm{Fgfl} 4^{-/-}$mice. In the mPFC there was no significant difference between genotypes in mRNA levels for each gene analyzed ( $t$ test, $p>0.05$; Fig. 10A). Furthermore, the mRNA levels of $\mathrm{Drdl}$, Drd2 and Slc6a3 did not change also for Acb and $\mathrm{CPu}$ in $\mathrm{Fgfl} 4^{-/-}$mice (t test, $\mathrm{p}>0.05$; Fig. $9 \mathrm{~B}$ and $\mathrm{C}$ respectively). These results demonstrate that the postsynaptic expression of receptors and transporters of the dopaminergic system is intact in $\mathrm{Fgfl}^{-/-}$mice, ruling out a possible major determinant of behavioral abnormality.

\section{DISCUSSION}

Previous reports on human mutations or variants of FGF14 indicate a correlation with aggressivity [33] and drug addiction [4-5,9]. Several studies on $F g f 14^{-/-}$mice suggest that this gene might be involved in fine tuning of neuronal activity in circuits controlling spatial working memory and susceptibility to drug addiction [19-21]. The current study was performed to explore whether the 
lack of Fgfl4 in mice is relevant for deficits in several behaviors ranging from aggressivity, to sexual behavior, sociability and spontaneous locomotion.

Our results confirm this hypothesis by showing that $\mathrm{Fg} f 4^{-/-}$mice have a marked reduction of aggressivity and sexual behavior. The normal social interaction of $F g f l 4^{-/-}$with wild type mice suggests that the reduced level of aggressivity and sexual behavior is not due to deficits in social interaction between mice. Moreover, the normal levels of locomotor activity, observed in the open field test, also rule out the hypothesis that these deficits are caused by a reduced motor activity of mice in a novel environment. In addition, other behaviors driven by spontaneous initiative are also reduced in $\mathrm{Fgfl}^{-/-}$mice. These include burying novel objects and spontaneous digging and climbing. However, in the open field test, that evaluates the spontaneous locomotion in an arena, generally considered as a measure of the general level of activity and related to exploratory behavior [34], $\mathrm{Fgfl} 4^{-/-}$mice travel the same distance as control wild-type littermates. It is possible that the reduced number of marbles buried is due to a reduced propensity of $\mathrm{Fgfl}^{-/-}$mice to dig. Moreover, rearing, which is also related to exploratory activity [34], was more frequent in $\mathrm{Fg} f 4^{-/-}$ mice, indicating that the decrease was specific for behaviors like burying, digging and climbing. Rearing is also related to anxiety, because during this behavior the animal might be more vulnerable to predators [34]. However, $\mathrm{Fgfl4^{-/ }}$ male mice showed the same propensity to walk in the center as wild-type mice, suggesting that anxiety is not significantly affected. The different consequence of Fgf14 deletion on behaviors directed toward an object (burying, digging, climbing), relative to exploratory activity (locomotion, rearing), indicates that this gene specifically controls goal directed behaviors rather than unaimed, exploratory movements.

Our results show that Fgf14 is important for the control and modulation of sexual behavior, aggressivity and spontaneous behaviors toward targets like burying objects, digging and climbing. Regarding the mechanisms of these actions, it should be noted that Fgf14 controls neuronal excitability by modulating $\mathrm{Nav}$ channels by direct interaction [16,35-36] and neurotransmitter release by mechanisms, which are not yet completely clear [37-38]. Fgf14 increases neuronal excitability and action potential firing [35-36] with effects, which are Nav-subtype-specific [17]. Since each type of neuron expresses a specific repertoire of $\mathrm{Nav}$ channels, the modulation of membrane excitability by Fgf14 differs across neurons, with consequences, which are difficult to predict. For example, in the CA1 area of the hippocampus, Fgf14 deletion causes an alteration of inhibitory postsynaptic currents and a selective loss of some parvabumin-positive GABAergic interneurons. Similar alterations have been found in psychiatric disorders like schizophrenia [21]. Future studies are necessary to test whether similar alterations are also present in the brain regions involved in the behaviors, shown to be altered by this report. The modulation of neurotransmitter release by Fgf14 [37-38] adds further complexity to the control of signal processing in neuronal networks. Our finding that several types of behavior are impaired by the lack of Fgf14 opens a 
novel path in the field of investigation on the molecular mechanisms implied in sexual behavior, aggressivity and spontaneous behaviors such as burying, digging and climbing. This suggests that fine tuning of neuronal function by Fgf14 is an important mechanism of control for several behaviors in mice.

\section{ACKNOWLEDGMENTS}

FUNDING. The research was funded by a grant of the University of Torino (Local Research Grant, FY 2015). There are no potential conflicts of interest to declare.

\section{REFERENCES}

[1] K. Hashikawa, Y. Hashikawa, A. Falkner, D. Lin, The neural circuits of mating and fighting in male mice. Curr. Opin. Neurobiol. 38 (2016) 27-37.

[2] J.C. van Swieten, E. Brusse, B.M. de Graaf, E. Krieger, R. van de Graaf, I. de Koning, A. MaatKievit, P. Leegwater, D. Dooijes, B.A. Oostra, P. Heutink, A mutation in the fibroblast growth factor 14 gene is associated with autosomal dominant cerebellar ataxia. Am. J. Hum. Genet. 72 (2003) 191-199.

[3] E. Brusse, I. de Koning, A. Maat-Kievit, B.A. Oostra, P. Heutink, J.C. van Swieten, Spinocerebellar ataxia associated with a mutation in the fibroblast growth factor 14 gene (SCA27): A new phenotype. Mov. Disord. 21 (2006) 396-401.

[4] Q-R. Liu, T. Drgon, C. Johnson, D. Walther, J. Hess, G.R. Uhl, Addiction molecular genetics: 639,401 SNP whole genome association identifies many "cell adhesion" genes. Am. J. Med. Genet. Part B 141B (2006) 918-925.

[5] T. Drgon, C.A. Johnson, M. Nino, J. Drgonova, D.M. Walther, G.R. Uhl, "Replicated" genome wide association for dependence on illegal substances: genomic regions identified by overlapping clusters of nominally positive SNPs. Am. J. Med. Genet. Part B 156 (2010) 125-138.

[6] K.J. Brennand, A. Simone, J. Jou, C. Gelboin-Burkhart, N. Tran, S. Sangar, Y. Li, Y. Mu, G. Chen, D. Yu, S. McCarthy, J. Sebat, F.H. Gage, Modelling schizophrenia using human induced pluripotent stem cells. Nature 473 (2011) 221-225.

[7] E.C. Verbeek, I.M. Bakker, M.R. Bevova, Z. Bochdanovits, P. Rizzu, D. Sondervan, G. Willemsen, E.J. de Geus, J.H. Smit, B.W. Penninx, D.I. Boomsma, W.J. Hoogendijk, P. Heutink, A 
fine-mapping study of 7 top scoring genes from a GWAS for major depressive disorder. PLoS One 7 (2012) e37384.

[8] A.M. Hunter, A.F. Leuchter, R.A. Power, B. Muthén, P.J. McGrath, C.M. Lewis, I.A. Cook, H.A. Garriock, P. McGuffin, R. Uher, S.P. Hamilton, A genome-wide association study of a sustained pattern of antidepressant response. J. Psychiatr. Res. 47 (2013) 1157-1165.

[9] J.R. Spencer, K.M. Darbyshire, A.A. Boucher, M.A. Kashem, L.E. Long, I.S. McGregor, T. Karl, J.C. Arnold, Novel molecular changes induced by Nrg1 hypomorphism and Nrg1-cannabinoid interaction in adolescence: a hippocampal proteomic study in mice. Front. Cell. Neurosci. 7 (2013) 15.

[10] H.M. Chen, C.J. DeLong, M. Bame, I. Rajapakse, T.J. Herron, M.G. McInnis, K.S. O'Shea, Transcripts involved in calcium signaling and telencephalic neuronal fate are altered in induced pluripotent stem cells from bipolar disorder patients. Transl. Psychiatry 4 (2014) e375.

[11] J. Di Re, P.A. Wadsworth, F. Laezza, Intracellular Fibroblast Growth Factor 14: Emerging Risk Factor for Brain Disorders. Front. Cell. Neurosci. 11 (2017) 103.

[12] D.M. Ornitz, N. Itoh, Fibroblast growth factors. Genome Biol. 2 (2001) REVIEWS3005.

[13] C. Liu, S.D. Dib-Hajj, S.G. Waxman, Fibroblast growth factor homologous factor 1B binds to the $\mathrm{C}$ terminus of the tetrodotoxin-resistant sodium channel rNav1.9a (NaN). J. Biol. Chem. 276, (2001) 18925-18933.

[14] C.J. Liu, S.D. Dib-Hajj, , M. Renganathan, T.R. Cummins, S.G. Waxman, Modulation of the cardiac sodium channel $\mathrm{Na}_{\mathrm{v}} 1.5$ by fibroblast growth factor homologous factor 1B. J. Biol. Chem. 278 (2003) 1029-1036.

[15] E.K. Wittmack, A.M. Rush, M.J. Craner, M. Goldfarb,, S.G. Waxman, S.D. Dib-Hajj, Fibroblast growth factor homologous factor 2B: association with Nav1.6 and selective colocalization at nodes of ranvier of dorsal root axons. J. Neurosci. 24 (2004) 6765-6775.

[16] J.Y. Lou, F. Laezza, B.R. Gerber, M. Xiao, K.A. Yamada, H. Hartmann, A.M. Craig, J.M. Nerbonne, D.M. Ornitz, Fibroblast Growth Factor 14 is an Intracellular Modulator of VoltageGated Sodium Channels. J. Physiol. 569 (2005) 179-193

[17] F. Laezza, A. Lampert, M.A. Kozel, B.R. Gerber, A.M. Rush, J.M. Nerbonne, S.G. Waxman, S.D. Dib-Hajj, D.M. Ornitz, FGF14 N-terminal splice variants differentially modulate Nav1.2 and Nav1.6-encoded sodium channels. Mol. Cell. Neurosci. 42 (2009) 90-101. 
[18] Q. Wang, D.G. McEwen, D.M. Ornitz, Subcellular and developmental expression of alternatively spliced forms of fibroblast growth factor 14. Mech. Dev. 90 (2000) 283-287.

[19] Q. Wang, M.E. Bardgett, M. Wong, D.F. Wozniak, J. Lou, B.D. McNeil, C. Chen, A. Nardi, D.C. Reid, K. Yamada, D.M. Ornitz, Ataxia and paroxysmal dyskinesia in mice lacking axonally transported FGF14. Neuron 35 (2002) 25-38.

[20] D.F. Wozniak, M. Xiao, L. Xu, K.A. Yamada, D.M. Ornitz, Impaired spatial learning and defective theta burst induced LTP in mice lacking fibroblast growth factor 14. Neurobiol. Dis. 26 (2007) 14-26.

[21] T.K. Alshammari, M.A. Alshammari, M.N. Nenov, E. Hoxha, M. Cambiaghi, A. Marcinno, T.F. James, P. Singh, D. Labate, J. Li, H.Y. Meltzer, B. Sacchetti, F. Tempia,, F. Laezza, Genetic deletion of fibroblast growth factor 14 recapitulates phenotypic alterations underlying cognitive impairment associated with schizophrenia. Transl. Psychiatry 6 (2016) e806.

[22] J.J. Clifford, A. Usiello, D. Vallone, A. Kinsella, E. Borrelli, J.L. Waddington, Topographical evaluation of behavioural phenotype in a line of mice with targeted gene deletion of the $\mathrm{D}_{2}$ dopamine receptor. Neuropharmacology 39 (2000) 382-390.

[23] F.R. D'Amato, R. Rizzi, A. Moles, A model of social stress in dominant mice: effects on sociosexual behaviour. Physiol. Behav. 73 (2001) 421-426.

[24] E. Egecioglu, L. Prieto-Garcia, E. Studer, L. Westberg, E. Jerlhag, The role of ghrelin signalling for sexual behaviour in male mice. Addict. Biol. 21 (2016) 348-359.

[25] E. Studer, J. Näslund, E. Andersson, S. Nilsson, L. Westberg, E. Eriksson, Serotonin depletioninduced maladaptive aggression requires the presence of androgens. PLoS One 10 (2015) $\mathrm{e} 0126462$.

[26] M. Yang, J.L. Silverman, J.N. Crawley, Automated three-chambered social approach task for mice. Curr. Protoc. Neurosci. (2011). doi: 10.1002/0471142301.

[27] C.A. Hoeffer, W. Tang, H. Wong, A. Santillan, R.J. Patterson, L.A. Martinez, M.V. TejadaSimon, R. Paylor, S.L. Hamilton, E. Klann, Removal of FKBP12 enhances mTOR-Raptor interactions, LTP, memory, and perseverative/repetitive behavior. Neuron 60 (2008) 832-845.

[28] Paxinos, G., \& Franklin, K. B. J. (2001). The mouse brain in stereotaxic coordinates. New York: Academic. 
[29] C. Jacobs, W. Van Den Broeck, P. Simoens, Increased volume and neuronal number of the basolateral nuclear group of the amygdaloid body in aggressive dogs. Behav. Brain Res. 170 (2006) 119-125.

[30] D.A. Pardini, A. Raine, K. Erickson, R. Loeber, Lower amygdala volume in men is associated with childhood aggression, early psychopathic traits, and future violence. Biol. Psychiatry 75 (2014) 73-80.

[31] E.F. Coccaro, R. Lee, M. McCloskey, J.G. Csernansky, L. Wang, Morphometric analysis of amygdala and hippocampus shape in impulsively aggressive and healthy control subjects. J. Psychiatr. Res. 69 (2015) 80-86.

[32] S. Thijssen, A.P. Ringoot, A. Wildeboer, M.J. Bakermans-Kranenburg, H. El Marroun, A. Hofman, V.W. Jaddoe, F.C. Verhulst, H. Tiemeier, van M.H. Ijzendoorn, T. White, Brain morphology of childhood aggressive behavior: A multi-informant study in school-age children. Cogn. Affect. Behav. Neurosci. 15 (2015) 564-577.

[33] Y. Zhang-James, S.V. Faraone, Genetic architecture for human aggression: A study of genephenotype relationship in OMIM. Am. J. Med. Genet. Part B 171 (2016) 641-649.

[34] W.E. Crusio, Genetic dissection of mouse exploratory behaviour. Behav. Brain Res. 125 (2001) 127-132.

[35] M. Goldfarb, J. Schoorlemmer, A. Williams, S. Diwakar, Q. Wang, X. Huang, J. Giza, D. Tchetchik, K. Kelley, A. Vega, G. Matthews, P. Rossi, D.M. Ornitz, E. D'Angelo, Fibroblast growth factor homologous factors control neuronal excitability through modulation of voltage-gated sodium channels. Neuron 55 (2007) 449-463.

[36] F. Laezza, B.R. Gerber, J.Y. Lou, M.A. Kozel, H. Hartman, A.M. Craig, D.M. Ornitz, J.M. Nerbonne, The FGF14 ${ }^{\mathrm{F} 145 \mathrm{~S}}$ mutation disrupts the interaction of FGF14 with voltage-gated $\mathrm{Na}^{+}$ channels and impairs neuronal excitability. J. Neurosci. 27 (2007) 12033-12044.

[37] H. Yan, J.L. Pablo, G.S. Pitt, FGF14 regulates presynaptic $\mathrm{Ca}^{2+}$ channels and synaptic transmission. Cell reports 4 (2013) 66-75.

[38] F. Tempia, E. Hoxha, G. Negro, M.A. Alshammari, T.K. Alshammari, N. Panova-Elektronova, F. Laezza, Parallel fiber to Purkinje cell synaptic impairment in a mouse model of spinocerebellar ataxia type 27. Front. Cell. Neurosci. 9 (2015) 205. 


\section{FIGURE LEGENDS}

Fig. 1 Experimental timeline showing the sequence of behavioral tests delivered to the animals.

Fig. 2 Rearing behavior observed in 10 min session. A-C. Rearing-wall behavior: Bars represent mean \pm SEM of $(A)$ rearing-wall time $(p<0.05)$, (B) number of episodes and $(C)$ duration of each rearing-wall episode $(\mathrm{p}<0.001)$. Rearing central structure behavior (D-F): (D) rearing-central structure time $(p<0.01)$, (E) number of episodes $(p<0.05)$ and $(F)$ duration of each rearing-central structure episode $(p<0.001)$. Free rearing behavior $(G-I)$ : $(G)$ free rearing time, $(H)$ number of episodes and (I) duration of each free rearing episode of $(p<0.05)$.

Fig. $3 \mathrm{Fgfl}^{-/-}$mice show a reduction in digging behavior. (A) Time spent in digging behavior (p < 0.01). (B) Number of digging episodes $(p<0.001)$. (C) Duration of each digging episode $(p>$ $0.05)$.

Fig. $4 \mathrm{Fgfl}^{-/-}$mice show a reduction in climbing behavior. (A) Bars represent mean $\pm \mathrm{SEM}$ of total time spent climbing during the $10 \mathrm{~min}$ session. The total time spent climbing is significantly reduced compared to wild type mice $* \mathrm{p}<0.05$. (B) $\mathrm{Fgfl} 4^{-/-}$mice display a reduced number of climbing episodes $* * p<0.01$. (C) Bars show no significant difference between genotypes in the mean duration of each climbing episode $\mathrm{p}>0.05$.

Fig. $5 \mathrm{Fg} f 14^{-/-}$mice bury a smaller number of marbles in 30 minutes of test compared to their wild type littermates. The bars represent mean \pm SEM. *** $\mathrm{p}<0.001$

Fig. $6 \mathrm{Fgfl} 4^{-/-}$male mice show a reduced sexual interaction. (a) The latency for sexual interaction is increased while the mounting duration is decreased (b). The number of mounts (c), and the duration of each episode (d) are significantly fewer in $\mathrm{Fgfl}^{-/-}$mice compared to their wild type littermates. (e) The number of males that had a sexual approach was significantly lower in Fgfl $4^{-/-}$mice. Fgfl4/- mice during the test spent more time in passive behavior (f). The bars represent mean $\pm \mathrm{SEM} .{ }^{*} \mathrm{p}$ $<0.05 ; * * \mathrm{p}<0.01 ; * * * \mathrm{p}<0.001$.

Fig. $7 \mathrm{Fgfl} 4^{-/-}$male mice show a reduced aggressivity in the resident intruder test. Bars represent means \pm SEM of time (in seconds) spent in attack (a) and threat (d), number of episodes for attack (b) and threat (e), and mean duration of each episode for attack (c) and threat (f). (g) Duration of social behavior exhibited during the test. (h) Relative duration of inter-individual interaction types. 
(i) Representative Nissl-stained sections used to measure the size of the amygdala (calibration bar: $250 \mu \mathrm{m}$ ). (j) Volume of the amygdala in $\mathrm{Fgfl} 4^{-/-}$and wild type mice. The bars represent mean \pm SEM. $* \mathrm{p}<0.05 ; * * \mathrm{p}<0.01 ; * * * \mathrm{p}<0.001$.

Fig. $8 \mathrm{Fgfl} 4^{-/-}$male mice show normal sociability, locomotor activity, exploratory behavior and time in center. (a) In the three chambers test both wild type and $\mathrm{Fgfl} 4^{-/-}$mice show a preference for a stranger mouse relative to an object (an empty wire cup identical to the one used to restrict the stranger mouse). (b) (left) In a novel open arena the locomotor activity related to the exploratory behavior and (right) the time in center are indistinguishable in $\mathrm{Fgfl4^{-/ }}$ relative to wild type mice. The bars represent mean \pm SEM. $* * \mathrm{p}<0.01$.

Fig. $9 \operatorname{Drd} 1, \operatorname{Drd} 2$ and $\operatorname{Slc} 6 a 3$ gene expression in the $\operatorname{mPFC}(\mathrm{a}, \mathrm{d}, \mathrm{g}), \mathrm{Acb}(\mathrm{b}, \mathrm{e}, \mathrm{h})$ and $\mathrm{CPu}(\mathrm{c}, \mathrm{f}, \mathrm{i})$ in wild type and $\mathrm{Fgfl} 4^{-/-}$mice. There were no significant changes for each gene expression in all the brain regions analyzed. Data are expressed as mean $\pm \mathrm{SEM}$.

\section{TABLES}

Table I. Analysis of 10 minutes of spontaneous behavior ( $\mathrm{n}=12$ for wild type and Fgf14 -/mice). For each behavior, total time, number of episodes and episode mean time are reported. ${ }^{*} \mathrm{p}<0.05,{ }^{* *} \mathrm{p}<0.01,{ }^{* * *} \mathrm{p}<0.001$.

Table II. Analysis of 15 minutes of resident intruder test $(n=14$ for wild type and $n=16$ for Fgfl $4^{-/-}$mice. ${ }^{*} \mathrm{p}<0.05, * * \mathrm{p}<0.01, * * * \mathrm{p}<0.001$.

Table III. Analysis of 15 minutes of sexual behavior ( $\mathrm{n}=14$ for both genotypes). ${ }^{*} \mathrm{p}<0.05,{ }^{* *} \mathrm{p}<$ $0.01, * * * \mathrm{p}<0.001$. 